Journal of Universal Language 8

March 2007, 91-127

\title{
A Discourse-oriented Model for Analysing Power and Politeness in Negotiation Interaction: A Cross-linguistic Perspective
}

\author{
Shamala Paramasivam \\ University Putra Malaysia
}

\begin{abstract}
This paper draws on linguistic theories that have universal statusLocher's (2004) approach to power, Brown and Levinson's (1987) theory for politeness, Watts' (1991) notion of social network and Goffman's $(1974,1981)$ understanding of frame - in order to develop a model that enables power and politeness to be analysed through language use in negotiation interaction. The model forwards a theoretical framework as well as a method for analysis that enables the identification and delineation of power practices in negotiation discourse. Together, the theoretical framework and the method for analysis form a microscope that facilitates a discourse analysis of power and politeness in negotiation talk. Data from negotiation interaction between Malay and Japanese businessmen are presented to illustrate the model.
\end{abstract}

Keywords: qualitative research design, discourse analysis, power and politeness, negotiation discourse 


\section{Introduction}

This paper provides a way of looking at power practices in negotiation interaction. It forwards a theoretical framework and a method for analysis that enables these practices to be identified and located in discourse, and captures their effects on the process and outcome of negotiation. Taken together, the theory and method provide a kind of microscope that enables power practices to be located and delineated. The notion of a microscope was introduced by Davis (1988) who found that "the analysis of power in interaction requires, in fact, a microscope" (Davis 1988: 349) because she discovered that to locate and investigate power struggles and how they are constructed and sustained in and through talk is by no means a straightforward affair.

The model put forth is based on the research design developed for my doctoral research on the study of power and politeness in business negotiations between Malay and Japanese businessmen (Paramasivam 2004). The aim of my investigation was to show how power and politeness enacted through language works in negotiation talk, in particular, how they are exercised and how they affect the process and outcomes of negotiation. The concerns of my study were, firstly, to examine the types of speech acts and discourse strategies employed for negotiating, and how they functioned as negotiation strategies from the perspective of power and politeness. Secondly, the study looked into how the display of power and politeness influenced the process and outcomes of the negotiation interaction, with respect to whose interests and what interests were privileged.

The research employs pragmatics as the selected approach within discourse analysis as the main analytic approach, and it is supported by speech act theory as a secondary approach. The research is qualitative in design employing a triangulation of theoretical perspectives and research methods (Flick 1998). The research draws 
on linguistic theories of universal status mainly Locher's (2004) approach to power, Brown and Levinson's (1987) theory to politeness, Watts' (1991) notion of social network and Goffman's (1974, 1981) understanding of frame. In the following sections, I offer the theoretical framework and the method established for the discourse analysis, introduce the data, and provide a discussion which can account for the exercise of power and politeness observed.

\section{Theoretical Framework}

As noted above, this framework was generated eclectically from various sources to suit the aims of the study. It is made up of 1) a tabulated list of speech acts and discourse strategies for negotiation, 2) Locher's (2004) checklist for the nature and exercise of power, 3) Brown and Levinson's (1987) theory for politeness, 4) Watts' (1991) notion of social network, and 5) Goffman's (1974, 1981) understanding of frame. Together hese theories, culled from a comprehensive review of the literature, function as a lense of a microscope that allow the exercise of power and politeness to be located and their workings in interaction to be investigated.

\subsection{A Tabulated List of Speech acts and Discourse Strategies for Negotiation}

Negotiation involves reaching an agreement acceptable to the parties concerned. As a result, it involves, firstly, making known each party's objectives, preferences, proposals or offers. If necessary, the parties then attempt to narrow differences between their positions, so that an acceptable agreement or settlement can be accomplished. Narrowing differences involves collaboration, adjustment, concession-making and bargaining. The primary speech functions of negotiating therefore are actions in, 
a. positioning the parties relative to each other, and

b. narrowing the differences between parties until a mutual agreement is reached.

(Mulholland 1991, Marriott 1995, Rehbein 1995, Savage, Blair, \& Sorenson 1999)

This is what constitutes negotiation actions. Based on this understanding, the central speech functions of negotiation were culled from the literature and tabulated in the list below, which was then used as a guide for the identification and analysis of speech acts in the data.

In a similar vein, a list of relevant discourse strategies was established as a base for the identification and analysis of discourse strategies for negotiation. Nonverbal features including paralanguage, kinesics and proxemics are not included in the list as these did not emerge as significant strategies for negotiation in the pilot study nor in the study proper of this research. In using the list, however, a researcher has to be aware that it functions only as a template for analysis and that he/she has to be open to empirical phenomenon other than those in the list in order to understand how the interactions are constructed in the context observed.

\section{Tabulated List of the Speech Acts and Discourse Strategies for Negotiation}

$\underline{\text { Speech Acts }}$

a. to establish and modify objectives, preferences, proposals or offers

b. to assert and justify viewpoints

c. to clarify viewpoints

d. to counter and oppose viewpoints

e. to request for and give information

f. to compare and contrast options

g. to evaluate ideas and opinions 
h. to call for agreement

i. to give reasons for agreement and disagreement

$\underline{\text { Discourse Strategies }}$

a. inductive and deductive rhetorical strategies

b. topic control

c. backchannels

d. humour

e. question

f. hedges

g. repetition

h. silence

i. pauses

j. interruption

The list above was very helpful to extract the language used for negotiation. However, in order to identify language for negotiation that was linked to power and politeness a theory for power and politeness that was sophisticated and comprehensive enough to help locate and investigate the phenomenon at the level of interaction was needed. Locher's checklist for the nature and exercise of power and Brown and Levinson's theory for politeness provided the necessary support. Both are discussed below.

\subsection{Locher's (2004) Checklist for the Nature and Exercise of Power}

Locher (2004) approached power in an eclectic way in order to be able to locate it in discourse. Her checklist for power (Locher 2004: 39-40) is as follows: 


\section{Locher's (2004) Framework for the Nature and Exercise of Power}

- Power is (mostly) expressed through language.

- Power cannot be explained without contextualization.

- Power is relational, dynamic and contestable.

- The interconnectedness of language and society can also be seen in the display of power.

- Freedom of action is needed to exercise power.

- The restriction of an interactant's action-environment often leads to the exercise of power.

- The exercise of power involves a latent conflict and clashes of interest, which can be obscured because of a societies' ideologies.

- The exercise of power is often accomplished by displays of relational work and politeness in order to maintain the social equilibrium and to negotiate identities.

This framework is found suitable for an analysis of power in negotiation discourse because power is located primarily in a combination of clashes of interests between participants (Proposition 7) and a restriction in their action environments (Proposition 6), both of which reflect on disagreement, which is the hallmark for negotiating activity. The main criterion for negotiating activity, as I noted in 2.1 above, is in the conflict of interests between participants. Negotiating begins with disagreement or non-alignment as a result of incompatible goals or clashes in interests between participants. In resolving disagreement, the exercise of power is likely to be involved as a tool to privilege interests. Power, as a result, has the probability for occurrence when there is disagreement.

The notion of restriction or constraint on the recipient of power is of relevance for the identification and analysis of power in negotiation interaction. The notion enhances the strength in the use of disagreement as a criterion for identifying power in negotiation 
discourse. Disagreement by its nature restricts the actionenvironment of the addressee by way of what he can say or do because "it creates a slot in which an answer to the content of the disagreement is expected" (Locher 2001: 3). Disagreement as a result constitutes both a conflict in interests and a restriction on the action environment. Because disagreement and power both reside in a conflict in interests and a restriction on the action environment, one can be used as identification for the other. For the objectives of this study, because disagreement is criterion for negotiation, Locher's call for the use of the presence of a conflict in interests combined with the action restriction for an identification of power, renders her framework suitable for this research.

Another feature in Locher's checklist that is equally important for an analysis of power in negotiation discourse is the notion that politeness often co-occurs with power. Locher explains that power and politeness are linked in that politeness is often used as a strategy or tool to soften or redress the display of power. She notes the motivation for this is in maintaining the social equilibrium between the interactants, that is, in protecting their face needs. When power is exercised in a polite way interactants show consideration for their addressees' face needs as well as protect their own face. This is called relational work or face work. The display of power in verbal interaction therefore has the potential to co-occur with politeness, and this co-occurrence enables interactants to negotiate without endangering the social fabric of communication.(For further details of Locher's framework see Paramasivam 2006.)

Locher however did not combine Brown and Levinson's approach to politeness within her checklist as a result of certain weaknesses in their approach and instead proposed her own view of politeness as marked forms. Her framework for power nevertheless is flexible in the analysis of politeness because it makes the link between power and politeness in a general way. The framework therefore allows politeness to be examined by using other suitable 
models, and for the objectives of my study Brown and Levinson's model for politeness was found appropriate and was therefore used alongside Locher's framework for power.

\subsection{Brown \& Levinson's (1987) Theory of Politeness}

Brown and Levinson's approach is found most suitable for investigating politeness behaviour in negotiation interaction because the approach acknowledges conflict, especially in face threatening acts (FTAs). Since negotiation by its nature entails conflict, clashes in interest or disagreement between negotiators, and negotiating activity works towards settling the conflict and establishing common ground, power is likely to be displayed by the negotiators to privilege their interests for which relational work involving politeness will most probably be exercised as a way to redress power to maintain social harmony during the negotiating activity and to prevent negative consequences in the negotiation relationship. Because the face-management view to politeness is centralized on the notion of conflict and redress to conflict, I find it the most suitable approach to employ to address politeness in negotiation discourse. Their charts of positive politeness, negative politeness and off-record strategies are also found to be very useful to help trace politeness strategies in discourse.

Although Brown and Levinson's theory provides an appropriate way to approach politeness in negotiation discourse, nevertheless it has a major criticism against it; the concepts of positive and negative face do not address discourse behaviours of non-Western cultures such as the Asian cultures, where the underlying interactional focus is centred upon collectivism or group identity rather than individualism (Matsumoto 1989, Mao 1994). This criticism is of concern to the present study because the participants of the business negotiations observed comprise Asians, namely Malays and Japanese. 
Both societies are defined in terms of group membership and social hierarchy, and the emphasis underlying interaction is in harmony and interdependence (Hall 1966, Doi 1976, Matsumoto 1989, Watanabe 1993, Nakano 1995, Hofstede 1991, Omar 1995, Abdullah 1996).

Because the Asian cultural orientation is towards collectivism instead of individualism, the manner by which FTAs are redressed by Asians is argued to be different from Western cultures. It is argued that politeness strategies of non-Western cultures would be different from Western cultures (Matsumoto 1989, Moa 1994). However, I contend that Brown \& Levinson's model is still applicable.

This is because the relationship between the two negotiating parties (see section 4), i.e., University Business Centre (UBC) and JC, the Japanese company, is a profit motive oriented business relationship. It is not the close-knit relationship of trust characteristic of the relationship between members of a social group or an organization. Although UBC and JC share an interdependent relationship as a result of their control over certain variables (i.e., UPM (University Putra Malaysia) has control of agricultural resources that JC needs, while JC has control of technological advances and expertise that UPM would benefit from for developing its resources), they are nevertheless distinct, separate individual companies with their own interests and goals. So although the negotiating parties belong to collectivistic cultures, their relationship is one of business, which is not characteristic of excessive collectivism of the Asian sense of self. No doubt preserving group harmony would be part of their cultural make-up. They would be aware of their connection to each other and would tend to be conscious of the consequences of their utterances and actions on each other. But because they are in a business relationship and represent separate companies there is the simultaneous need to safeguard the interests and goals of their own companies. It is hard 
to imagine that in the negotiations they would forgo the possibility of a good deal for their companies simply for the sake of a harmonious group feeling. I hypothesize that although collectivism is part of their cultural make-up, because their relationship is one of business, their business tie lies on a continuum between collectivism and individualism. As a consequence of being dependent on each other for pursuing their business interests, the relationship is characteristic of interdependence. However, because they are separate organizations the relationship is also characteristic of individualism. It is a relationship of interdependence that requires them to maintain their independence as separate companies. The underlying orientation in the interactions therefore would be on balancing their involvement and their independence so that they get what they need from each other in order to expand their own businesses, while maintaining their interdependent relationship. They have to find just the right way of saying something for achieving their own best advantage without disrupting the harmony of their interdependence. Based on this argument, I contend that Brown and Levinson's theory can serve as a template to investigate how politeness is approached and realized by the participants of my study.

To further support my case I take Janney \& Arndt's (1993) argument that for politeness research to move forward, an interplay between universality and cultural relativity is necessary. They support the use of Brown and Levinson's theory as a base for the analysis of politeness in cultural contexts other than Anglo-Western. They (1993: 38) say,

A helpful beginning would perhaps be to start viewing Brown and Levinson's theory as a particularly clearly articulated wellreasoned account of politeness in a specifically Anglo-Western cultural context, and to use their findings as a set of baseline hypotheses for increasingly differentiated comparative studies of politeness phenomena in other cultural contexts. 
The findings of my study indeed display a deviation in the exercise of politeness in interaction from Brown and Levinson's scheme. In their view, power is not something different from politeness, but is a dimension of politeness phenomena, especially in face threatening acts. As a result, power is conceptualized as a potential dimension at work in a face threat and is thus part of politeness phenomena. Within the interactions of my study, however, power co-occurs with politeness as separate but interdependent moves; a power move is made which is then countered with a politeness move. Solidarity and deference politeness strategies also co-occur and work interdependently to address the face needs of the interlocutors. These are exemplified in the examples in section 5.

Although Locher's and Brown and Levinson's theories enable power and politeness, respectively, to be located and identified in verbal interaction, a methodological tool to capture the dynamic quality of power practices in interaction was still needed. Watts' (1991) social network and Goffman's $(1974,1981)$ frame provided the necessary tools for this.

\subsection{Watts' (1991) Notion of Social Network}

Watts distinguished two types of social networks in verbal interaction, latent network and emergent network. A latent network is a "static entity" (Watts 1991: 5), which represents the latent ties established between individuals. These ties "can be activated when the need arises and the conditions are favourable, but otherwise remain dormant" (Watts 1991: 155). A latent network between individuals who are meeting for the first time is formed at their first encounter, which then acts as a reference point for future encounters. The first encounter however also counts as an emergent network because it is also where the actual interaction is going on. In first encounters, therefore, latent and emergent networks correlate.

An emergent network is dependent on the latent network, except 
for first encounters where both co-occur. An emergent network is described as a "micro on-line" network, which is in "a constant state of flux" (Watts 1991: 155). It is dynamic and constantly changing. It is observable only during ongoing interaction. It is limited in duration to the time taken up by the interaction as well as in terms of floor control and topic development. Watts (1991: 177) uses the notion of topic development to trace and give evidence for an emergent network. The start of a topic or subtopic represents an emerging network. As a result, there may be smaller or sub emergent networks within an emergent network. However the whole interaction also functions as an emergent network.

Locher (2004) explains the distinction between an emergent network and a latent network allows the dynamics of an ongoing interaction to be captured more properly. She explains that in interaction, interactants carry over their role relationships and power situation from the previous encounter into the next. The links between the individuals are latent; in the emergent network however they can contest and negotiate their positions. While latent links are reproduced, they may be confirmed or challenged and changed in emergent networks. An emergent network is thus the place where power is negotiated in interaction.

Within my own study, latent and emergent networks are found to be pertinent for an understanding of power in negotiation discourse. They help to capture the dynamics of power in this genre. Negotiation as an event is dynamic. A negotiation relationship is made up of several negotiation encounters. Every encounter is only one step in the business relationship. They are only "a part of a whole, not an independent, complete entity" (Charles 1995: 172). Charles (1995) explains that every negotiation encounter takes off from the relationships established in the previous. Within an encounter, role relationships and power positions of negotiators constantly change. Because each encounter builds up on the previous ones, the links established in the previous encounter serve 
as latent links in the next encounter. Every encounter thus functions as an emergent network where role relationships and power positions are constantly negotiated, which then serve as a latent network for the next. Because of the dynamic nature of negotiation, the concept of latent and emergent networks can help capture the dynamics of power play among negotiators.

However in order to secure more accurately the dynamics of power in interaction, I complemented social network with frame. The connection between the two is discussed below.

\subsection{Goffman's $(1974,1981)$ Notion of Frame}

The notion of frame used for the objectives of the present study is Goffman's (1974, 1981). Goffman (1974: 8) describes a frame as a "definition of the situation" and an answer to the question "What is it that's going on here?", whether an utterance or move is intended as a joke, an insult, criticism, and so forth. He defines frames as "principles of organization which govern events - at least social ones - and our subjective involvement in them" (Goffman 1974: 10-11). Principles of organization are related to sociocultural norms and conventions in the performance of speech events. They specify such things like who can take part, what the role relationships are, what can be said, when it can be said, how it is to be said and so forth. They are the appropriate behaviours for an activity, and participants are expected to follow certain thematic progression and turn-taking rules and to produce certain outcomes. In order to interpret utterances in accordance with the way in which they are intended, hearers and speakers must be aware of the principles of organization of the activity they are engaged in.

In discussing frames, Goffman proposes that interactants have the ability to modify and shift frames in conversation. He introduces the term "footing" as "a way of talking about a change in our frame for events" (Goffman 1981: 128). Footing is a kind of frame that 
identifies the relationship between people. Goffman proposes that participants shift their footing within a single conversation (shifts are located through linguistic cues and markers) where their social character, status and positions remain relatively stable. Then, the shifts in alignments affect the participants' ways of speaking and interpreting what is intended. This is an important notion for this study as within the negotiation interactions during a meeting and between meetings there was constant change in role relationships between the negotiators involved. Their changes in footing exemplify the fluidity by which they maneuvered their interactions in accomplishing desired outcomes. The data in section 5 exemplify how shared principles of organization and footings play a role in interaction.

The relationship between frame and power is addressed by Rees et al. (1997) who postulate that because the frame constitutes shared understandings of linguistic and socio-cultural norms and conventions in verbal interaction, the frame can be used as an instrument to examine power relationships, which are regulated by the very same norms and conventions existing in interaction. They propose that the frame can reveal the discourse strategies of power, power differentials in strategy use, as well as how the strategies affect the interaction process and outcome by examining communicative action with regard to who spoke, with whom, how, for what reasons and with what effects.

Since both frame and social network can function as analytic tools to investigate power dynamics in interaction, I treated every social network as a frame and analyzed the interaction in each network by means of speaker-interlocutor response patterns in relation to who spoke, how, when, why, with whom and with what effects. This enabled a step-by-step display of how negotiation action takes place, how role relationships change within the interactions, where and how power is exercised, how it privileges the interests of the participants, and how the process and outcomes 
of the interactions are shaped.

To reiterate, the theoretical framework for my inquiry into power and politeness entailed an eclectic approach. These approaches were used in combination for the analysis of the data. The method for analysis is explained below in order to illustrate how the theories worked together in performing the analysis.

\section{Method for Data Analysis}

\subsection{Division of Negotiation Interactions}

Following transcription of the recorded data, the interaction in each negotiation meeting was divided into segments of talk with topic being the criterion for division. Each segment thus begins with the initiation of a topic, right through its discussion between the parties, up to its termination. A topic may sometimes be ended explicitly or it is sometimes denoted implicitly by the start of another topic. Sub topics that arose in the discussion of a main topic were included within the same segment. This is because they constituted negotiation action of the main topic.

Each segment of talk is referred to as an emergent network (Watts 1991). It is necessary to look at them as networks because it is within a network that the topic as well as power is negotiated. The power positions established within each network carries over into the next and become the starting point of the following network. The notion of network thus helps to gauge the dynamics of the interaction with respect to the exercise of power and politeness and their effects in negotiating the topic under discussion. The analysis revealed that the exercise of power was illustrated in every emergent network, and each network told a mini-story about power and politeness and their effects on negotiation action.

In order to make visible the dynamics of the negotiation action, 
the emergent networks within each meeting were linearly sequenced, beginning with the first topic and proceeding to the last. This is important because as I mentioned above one segment of talk has an impact on what occurs in the next and so on. A linear sequencing of emergent networks would display the flow of negotiation action, and the exercise of power and politeness and their effects on the negotiation.

\subsection{Identification of Disagreement Sites}

In order to identify the disagreement sites within each network an identification procedure was employed. This involved noting topics over which there were differences of interests between parties. These topics were first noted during the observations of the meetings. The minutes of the meetings also served to identify the topics over which there were disagreements. The actual disagreement sites were then identified using Locher's proposition that a disagreement involves a combination of conflicts in interests between participants as well as restrictions on their action environments (Propositions 6 and 7 in her framework). This was then verified through interviews with the participants.

\subsection{Procedure for Data Analysis}

After the relevant disagreement sites were identified and verified, they were analysed. This involved several stages.

The first stage of analysis entailed a close reading of the networks in order to make visible the dynamics of the negotiation action. This entails a microscopic line-by-line analysis of the interaction. It involves showing how the interactants' utterances influenced each other from the perspective of power and politeness. This was accomplished using frame (Goffman 1974, 1981) as an approach. Every network functioned as a picture frame. The 
dynamics of each network was captured through speakerinterlocutor response patterns. Communicative action with regard to who spoke with whom, when, how, why and with what effects were noted to establish speaker-interlocutor response patterns. This enabled a step-by-step and moment-by-moment display of how the negotiation action took place, where and how the exercise of power and politeness occurred, what role they played in privileging interests, and how they shaped the process and outcomes of the negotiation.

The second stage of analysis was to identify the speech acts and discourse strategies employed for negotiation. The tabulated list of speech acts and discourse strategies was used as a guide. In cases of multiple functions of utterances, the two solutions offered in the literature, namely 'the hearer knows best' principle, where responses of the hearer within the speech data are examined in order to gauge the intention and function of the speaker's utterances, and triangulation through interviews with participants were used. An analyst has also got to be open to other acts and discourse strategies of negotiation that may have been employed, particularly those that are culturally oriented to the participants. The acts and strategies that displayed power were identified using Locher's proposal that a combination of action-restriction and the presence of a conflict of clashes of interests primarily point to the exercise of power. The acts and strategies that exercised politeness were located through Brown and Levinson's understanding of positive and negative face, and the underlying politeness strategies employed were identified through their understanding of positive and negative politeness strategies. The acts and strategies were then described as to how they functioned as negotiation strategies from the perspective of power and politeness.

Two emergent networks are presented in section 5 to illustrate how my framework operates in the analysis of linguistic data. 


\section{Data Context}

The study was set in Malaysia, a multiracial, multicultural country with people of different racial origins and ethnic groups. Malays are the indigenous people and the dominant race followed by Chinese and Indians, two major races that migrated to this country in the $16^{\text {th }}$ century, and that now form the second and third largest groups of people in the country. There are also minority aboriginal groups such as Kadazans, Ibans, Dayaks, Muruts and others. Malaysia is described as a country with a dynamic and rapidly growing economy with bilateral and multilateral links particularly in joint venture partnerships with many countries in the world especially America, Japan, the European Union, Taiwan, Hong Kong, South Korea, Germany and the United Kingdom.

The business negotiation of this study was for the establishment of a joint venture between University Putra Malaysia (UPM), an established Malay academic organization of fifty years experience in agricultural research and development, and JC, a ten-year old medium-sized Japanese pharmaceutical company. JC approached UPM with the proposal for joint venture for drug discovery. The proposal was for UPM to supply agricultural resources to JC, that would then supply these resources to pharmaceutical companies in Japan for research and development in order to gauge potential ones for drug development. The venture therefore entailed the supply of agricultural resources by UPM to JC, which would function as the middle party between UPM and Japanese pharmaceutical companies in Japan.

There were differences in the power positions of the two parties involved. It is important to note these differences when investigating power. In the context of this study the more dominant party was UPM represented by its University Business Centre, henceforth $U B C$, and the subordinate party was JC. The power difference can be attributed to several factors. firstly, UPM is a large and 
established tertiary institution in the country, backed by fifty years of experience in agricultural research. As such, it is able to command more power, and especially so in the area of agricultural and pharmaceutical research, than the medium-sized company, JC, that was founded only ten years ago. Secondly, since it was JC that approached UBC with a business proposition, JC is in a more vulnerable position than $\mathrm{UBC}$, as the former is dependent on UBC for the approval and acceptance of its proposal. Thirdly, since the business negotiation meeting was held at UPM, its officers played the role of hosts while the JC representatives were their guests. As hosts, UPM officers had certain rights and obligations, which placed them in a more dominant position. They could, for example, interrupt the meeting when food and drinks were served. The JC officers, on the other hand, were in their host's territory and could be expected to adjust themselves to their role of guests.

Three meetings between the negotiating parties (UPM and JC) were observed and audio taped over a period of thirteen months, resulting in a copious amount of talk. However for the purposes of this study three hours and fifteen minutes of talk were deemed sufficient. The meetings were all conducted in English. The key negotiators were A1, the Managing Director of UBC, UPM, a 55year old male Malay professor who has served the university for twenty-five years, and B1, the Chief Executive Officer of JC, who is a 35-year old Japanese businessman with ten years experience. Other participants in the negotiations were A2, the male Malay Director of UBC, who is 35 years old with ten years of working experience as an officer at UPM, and subordinate to A1. B2 is a 25year-old male Chinese Malaysian who worked for two years as General Manager at JC. Both A2 and B2 played supportive roles in backing their superiors. 


\section{Data and Discussion ${ }^{1}$}

The network below is a 3-minute exchange between the two key negotiators (A1 and B1) of the negotiation observed during their first meeting in April 2001. In this network, which is the second emergent network within the business negotiation as a whole, A1 made a demand for intellectual property rights immediately after B1 forwarded his proposal for joint partnership in the network before this.

Example: Emergent Network 2: The demand for intellectual property rights

A1: Managing Director of UBC

B1: Chief Executive Officer of JC

113 A1: let me let me explain

114 B1: yes

115 A1: of course one of our as you know (.) job here as a business centre is in

116 research commercialization (.) we are also doing consultancy training

117 and other business ... so in terms of research

118 B1: yes

119 A1: commercialization (.) this is why all this biodiversity conventions now

1 The transcription guide below will be found useful when examining the data.

(.) : indicates a brief pause, approximately half a second or less.

(1.0), (1.5), (2.0): indicates a longer pause, shown as the number of seconds to one decimal place.

—:indicates overlapping speech i.e. two persons talking at the same time, includinginterruptions. 
Malaysia has instituted this intellectual property right now for the last

121 one hundred years (.) the British came get all our sample develop

122 product (.) and on the country does not get anything (.) one very good

123 product is Quinine you know that malaria pill (.) we lost in don't know

a billion dollar industry ah and then a lot of other product (.) the

125 Canadian British American just go into our forest get it out (.) they

126 manufacture (.) ah ubat (medicine) and all this then they forget about us (.)

127 that's why our country sign that bio-diversity convention ok so (.) this is

128 why we have to (.) when we are talking about about er research

129 collaboration this is the sticky pointlah intellectual property whose IP

130 is it ok UPM (.) collaborate with many organization (.) in the country

131 (.) like you said we are the leader in the country in terms of research in

132 agriculture, forestry, environment (.) so many organization and (.)

133 quite a number also from Japan ah Ministry and universities local I

134 myself do project with Yokohama National University yah but (.)

135 again like we said basic research if basic research is easy you know

136 there's no (.) like what I'm doing with Yokohama 
137

138

140

141

142

144

\section{National University}

is fine method (.) to reforest eh so when it's successful (.) then it's

joint intellectual property with Yokohama it's just basically research

producing papers but when it comes to getting a product or what so

even like you know the university medicinal also when you go into

business then we have to work out the details (.) you are actually a

consultant firm to all this companies very good we can make

contact with you and then you make contact but (.) when it

comes to this how do we do when it comes to research

when after three years four years we already got a product then you

want to sell it (.) what does the country get what does the university

get ah this is the thing if basic research just measuring trees planting

trees but when it comes to finding new species of trees suitable for

what area ah then it becomes er intellectual property so like I said we

have worked with many organizations and now the university is also

trying to find ways how to share the profit so that we just don't do

research and our people who do research do not just don't get 
anything we must also get something

154 B1: yes

155 A1: as far as collaboration we welcome with open arms (.) with open

156 heart (.) but when it comes to (.) er sharing the product sharing the

157 profit we always worry if we don't sit down and write the agreement properly ha (.) we have a few cases with Cambridge for example eh our researcher develop a pregnancy test or something like that (.)

160 then Cambridge said it's theirs (.) you know because we didn't sign

161 an agreement (.) but this researcher actually was doing $\mathrm{PhD}$ in

162 Cambridge (.) so Cambridge said it's their property (.) so they want

163 to commercialize it so because we didn't sign an agreement (.) ah we

164 lost to Cambridge even we lost our researcher who went back to

165 Cambridge as well (.) Malaysian (B1 laughs) ah and then er quite

166 quite a number of cases where the university and the country lost this

167 is why (.) er now even you want to go to a forest you cannot go now

168 without cooperation with local university and you probably have to

169 talk to FRIM or forest department (.) so that is one issue we have to

170 address the second one is (.) what product are you 


$\begin{array}{ll} & \text { talking about } \\ 171 & \text { what research are you talking about (.) last time } \\ & \text { we talk about } \\ 172 & \text { Roselle you know } \\ 173 \text { B1: } \quad \begin{array}{l}\text { that that is my own er interest but er at this } \\ \text { moment I'm working as a } \\ \text { consultant to the pharmaceutical companies so (.) } \\ \text { we are interested in } \\ \text { pharmaceutical product }\end{array} \\ \end{array}$

Treating the network as a frame, the communicative action of the network was analysed through speaker-interlocutor response patterns. The topic over which there was a conflict in interests was intellectual property rights. The tabulated list of speech acts helped identify the relevant acts in the network. The demand was indirectly advanced using speech acts of assertion, particularly 'to inform', 'to state' and 'to question'. The demand was first implied in lines 127130 using the speech act, 'to inform', "this is ... IP is it". A1 informed B1 about the issue of intellectual property rights in collaborative research. The demand was then repeated in lines 144147 , "when it ... university get". Using the question form, A1 again indirectly demanded for intellectual property rights. In lines 150-153, "now the ... get something" using the speech act 'to inform', the demand was again implied. A1 asserted that UPM was looking into ways to address the issue of intellectual property rights. The demand was implied the final time in lines 169-170 through the speech act 'to state' "so that ... to address". The demand was advanced four times and on all counts it was indirect.

After identifying the speech acts employed, Locher's checklist for the nature and exercise of power was used to locate where power had been exercised. By using Locher's claim that power resides in the combination of a clash of interests and in restrictions of action environments, it became clear that power was exercised in the 
speech acts used to advance the demand; 'to inform' (lines 127-130 and 150-153), 'to question' (lines $144-147$ ) and 'to state' (lines 169-170). The combination of informing, questioning and stating with demanding was action restrictive in that B1 was constrained into taking up the demand. This is evident in his lack of response throughout A1's discourse. The backchannel in line 154 is not agreement but merely that he is listening and paying attention to A1. The interview data confirmed that he was constrained into agreeing with A1's demand. B1's response on this issue, gathered at an interview with him, was, "we feel we have no choice we have to accept it (.) we understand UPM would like to be involved in the IPR as much as possible this is part of the bio diversity convention although we can't see at any point during this primary stage of research there will be any IPR issue (.) only when if the foreign collaboration party found any interesting compound in the sample it will touch about the IPR and from there it must be discussed further".

I noted in my framework the need to be open to empirical phenomenon other than those in the tabulated list in order to understand more fully how interactions are constructed in the context observed. The analysis of the network above revealed that other than the speech acts observed, power was also displayed through discourse strategies. Using the tabulated list of discourse strategies and with Locher's claim of what involves an exercise of power, I found that repetition, pauses and topic control were also strategies by which power was exercised other than speech acts. For instance, A1 conveyed his demand for intellectual property rights four times (lines 127-130, 144-147, 150-153 and 169-170). To convey a demand four times is a clear indication of power. Repetition emphasized the point about intellectual property rights that A1 wanted to make absolutely sure got across to B1. As a result B1's action environment was restricted to taking up the demand, so that A1 can be perceived as exercising power over B1. Power was 
also displayed in the discourse strategy, 'no pause + topic shift', in lines 169-172. After conveying his demand for the final time in lines 169-170, A1 immediately moved on to the next topic without pausing to allow for B1 to respond to his demand. His utterances were, "so that is one issue we have to address the second one is (.) what product are you talking about what research are you talking about (.) last time we talk about Roselle you know" (lines 169-172). It is conventional in interaction for the speaker to pause after advancing a proposition to allow for the interlocutor to respond. But in the interaction above, as I noted, A1 did not pause after he concluded his demand in line 169-170. Immediately after his demand, he initiated a new topic on the type of plant species B1 was interested in for joint research. This suggested that he did not want to discuss the matter of intellectual property rights with B1. He was unwilling to negotiate this matter any further. In other words, the matter of UPM's intellectual property rights in the joint venture was non-negotiable, and it was indicated in A1 holding the floor, not relinquishing it for $\mathrm{B} 1$ after the demand was made. The interview with $\mathrm{B} 1$ confirmed this interpretation. He noted that with regard to the issue of intellectual property rights, he felt he had no choice but to agree with UBC. The strategy was, thus, an exercise of power as the action environment of B1 was constrained into accepting the demand with no alternative choice since he was denied a chance to respond to the demand. B1 rightfully picked up this cue and maintained his footing within the interactions when he did not respond to the demand in his turn in lines 173-175.

There was interplay of power with politeness in the pattern employed for demanding. The demand was extended using the acts 'to inform', 'to question' and 'to state' along with the discourse strategies of repetition, and 'no pause + topic shift', all of which evidenced a concoction of power. However deference and solidarity politeness were also exercised.

Deference was displayed through indirection. Firstly the use of 
speech acts. The very same acts that displayed power (i.e. 'to inform', 'to question' and 'to state') also exercised deference by way of being indirect about the demand. By avoiding a direct, explicit, bald on record demand, A1 displayed face considerations for his addressee. Deference was given to the other party by not assuming his compliance to the demand. The underlying politeness strategy was “don't coerce H", “don't assume $\mathrm{H}$ is able/willing to do A" (Brown \& Levinson 1987: 131).

Other than these speech acts, the inductive rhetorical strategy was also a strategy for indirection. Before the demand was put forth, general background information to support the rationale for the demand was given. Four reasons justifying the demand were put forth as the demand was made. The first reason emphasized how Malaysia had lost out to the British and the Americans who had made use of Malaysian resources for the manufacture of medicines without compensating the country (lines 119-127). In the second (lines 130-141), third (lines 147-149) and fourth (lines 156-166) reasons, joint research projects between UPM and foreign companies, which resulted in losses to UPM were quoted as rationale for the demand. All the reasons served to convey A1's demand for intellectual property rights as a general rule in research collaboration that involves product development. This served as rationale for his demand. The demand was thus made by "mak(ing) the claim without impinging on the hearer, stat(ing) the claim as a general rule" (Brown and Levinson 1987: 131). The inductive structure facilitated the negotiation in that it not only mitigated the impact of demanding, but also gave the other party a feel of the situation and an understanding of the background behind the demand so that he (B1) would be receptive to the demand made.

In addition to deference, solidarity politeness was also displayed in A1's demanding pattern. Solidarity between the parties was emphasized through agreement with B1's proposal. Preceding the demand in lines 144-147, was agreement with B1's proposal for 
joint venture (lines 142-143). Agreement was repeated and upgraded in lines 155-156. Solidarity functioned as a negotiation strategy, in that by conveying UPM and JC as cooperators, the assertiveness inherent in demanding was softened. This served to maintain the harmony of the business relationship.

The analysis showed that the interplay of power with deference and solidarity politeness worked for A1. B1 not only accepted A1's demand for intellectual property rights, but the relationship between them was also preserved, despite the face threat inherent in demanding, and the power displayed in performing this FTA. This is evident in B1's response in lines 173-175. A1's change in topic after concluding his demand was taken up by B1 who responded to A1's question. Following B1's uptake of A1's change in topic there was no further talk on the topic of intellectual property rights. The interview data also, as mentioned, revealed that B1 had no negative feelings towards A1 and his demand, and perceived it as part of a general principle in joint research with UPM.

In sum, in the network above, the more powerful participant was A1 while the less powerful participant was B1. The clash of interest was over the issue of intellectual property rights. The exercise of power is evidenced by the use of directive and assertive speech acts when demanding such as 'to inform', 'to question' and 'to state', and discourse strategies of power such as repetition and the 'no pause + topic shift'. The combination established a constraining effect on B1, the recipient of power. His action environment, and action alternatives, was constrained into complying with the wishes and wants of A1, the exerciser of power. A1's display of power however was integrated with deference and solidarity politeness, both of which worked together to protect the harmony of the business relationship. Deference was exercised through the very same speech acts that exercised power by way of avoiding a direct, bald-on-record act, and the inductive rhetorical strategy. Solidarity was expressed through the act 'to agree'. The integration of power 
and politeness served as A1's interacting pattern at this stage of the negotiation.

I would like to note, however, that in subsequent networks within the same meeting as well as in subsequent meetings between the two parties, the dynamics of power between A1 and B1 could differ with shifting role and status relationships. B1 for instance may assume a more dominant position in the interactions while A1 may be reduced to a more subordinate position (this is evidenced in the next example presented below). The point to make is that within a negotiation, power is never static. It is always dynamic, relational and contestable because of constant change in roles as a result of how far the parties get in the business transaction and relationship. It is therefore pertinent that the framework employed for the analysis of power in negotiation discourse accounts for dynamism. The framework offered in this paper does just that in the adoption of Watts' social network and Goffman's frame for the analysis of the play of power.

Example: Emergent Network 8: The Involvement of Only Large Japanese Companies

470 A1: ... you also screen not not the plant but the company (.) find the the biggest company

mean the strongest company then we have no problem with yen later on

B1: no now

(.) because when - I

wanted to do this project ten years ago four companies wanted to work with me in forestry 
478

479

480

481

482

483

484

485

486

487

488

489

490

491

492

493

494

495

(.) so I screen also the companies and I choose Mitsubishi because

they are the biggest the richest —company (.) no

B1: problem after that

A1: (.) after signing money just comes (.) you see I'm not saying that

some companies are small and are just picking up

(.) but we

wanted to work with very really strong companies (.) and

Mitsubishi also has some logging interest in

Malaysia 5 you see

B1: $\quad$ ah yes

A1: so (.) ah we got a lot of money from them but they use a local

company (.) Daya (.) their job (.) just signing cheque only (3.0) I

don't know how you work but doesn't matter as long as we get

the money and then we have a three party agreement (.) you the

Japanese company and UPM (.) and then next time (.) we must

be clear what they want (.) what kind of product ah like I said ah

(.) plant agriculture plant forest plant er others all sorts (.) you

know thousand and thousand

B1: actually we are very much interested in microbes but the

microbes (.) quite difficult (.) because once you supply to them 
they can cultivate themselves

A1: in fact the product ah we want to get interested also in microbes

498 microbes are I don't know what (.) but for bioplastic only

$499 \quad$ B1: ah ha

500 A1: if we can make that (.) we can be billionaires already (.) the

501 whole world can be free of plastic (.) but it is not perfect yet (.) so

502 we want help also (.) you just imagine ha if UPM and your

503 company or the Japanese company can produce bio-plastic after

504

505 using put in the soil (.) disappear biodegradeable (.) biodegradeable ah (.) we can solve the world's environmental problems (.) there's one product and our researcher is working on it but stuck not reached perfection

In the network above, which is the eighth emergent network within the business negotiation, A1 proposed his idea for involving only large Japanese companies in the joint venture. He said, "you also screen ... the company (.) find the biggest company" (lines 470-471). This idea was first initiated in a previous network but was not taken up by B1. As a result, in this network, the proposal came across as a directive, explicit bald on record. This was a display of power. B1's action environment was constrained into complying with the directive. His response, "no no" (line 472), displays this, after which he proceeded to justify himself. He was, however, unable to justify himself as he was further constrained by A1 
through interruptions (line 473 and 476).

A1 interrupted him twice in order to justify his own proposal. A1 provided reasons to support the rationale for his proposal. In lines 473-474, his reason was that by involving big companies, there would be no problem in the receipt of payment. His utterances were, "then we have no problem with yen later on". In lines 476-481, he provided an example of a joint project between UPM and a large Japanese company, where receipt of payment was not a problem. He noted, "because when I wanted to do this project ten years ago four companies wanted to work with me in forestry (.) so I screen the companies and I chose Mitsubishi because they are the biggest the richest company (.) no problem after that (.) money just comes in (.) you see". The reasons claimed common ground with the other party by assuring reflexivity in their wants. The common want assumed was that both parties would want payment with a minimum of problems. This was a display of solidarity where the underlying politeness strategy was to "give reasons" as a way "to claim reflexivity, to convey that $\mathrm{S}$ and $\mathrm{H}$ are cooperators" (Brown \& Levinson 1987: 102).

However, the strategy failed to persuade B1 into mutual alignment. B1 responded with silence of approximately three seconds after A1 relinquished his turn. This implied disagreement on his part. This was confirmed in an interview with him, where he responded, "ah (laughs) actually there I wanted to tell him I don't see any problem with payment (.) you know (.) it's not a problem on our side and we have our headquarters in Japan to monitor the situation there so it is not going to be a problem with us you see". Silence, can be said to have been a display of power on his part, as it constrained A1 into reassessing his proposal. A1 withdrew his proposal, "I don't know how you work but doesn't matter as long as we get the money" (lines 487-489). He gave in and accommodated B1. Following this, he changed the topic of discussion and moved on with the negotiation. His utterances were, "and then (.) we have a 
three party agreement you the Japanese company and UPM (.) and then next time (.) we must be clear what they want (.) what kind of product like I said ah (.) plant agriculture (.) forest plant er others all sorts (.) you know thousand and thousand" (lines 489-493). He changed the topic of discussion to the joint venture, and the type of plant species for research.

Although A1 gave in to B1, there was nevertheless a display of power in A1's withdrawal. An explicit precondition was put across as he withdrew his proposal, "as long as we get the money"(lines 488-489). He also executed the topic shift without a pause to disallow B1 to take a turn following the withdrawal of his proposal. This signaled that the matter was closed and not open to further talk. With regard to the topic shift, on the topic of the joint venture, he confirmed that it was a three-party agreement, "we have a three party agreement you the Japanese company and UPM", while on the topic of plant species for research, he reminded the other party to be specific, "and then next time (.) we must be clear what they want (.) what kind of product like I said ah (.) plant agriculture (.) forest plant er others all sorts (.) you know thousand and thousand". The speech acts 'to confirm' and 'to remind' are dominant speech acts and the prerogative of the party in the higher social position. A1's display of power at this point was probably to regain his position in the network (and to save his own positive face), which was jeopardized as a result of B1's disagreement and he (A1) having had to give in to B1.

A1's efforts to reclaim his position in the network were ratified by B1, who adjusted his footing when he took up A1's change in topic and initiated a subtopic. In response to A1's reminder for being specific over the plant species for research, B1 initiated a subtopic on microbes. He noted his interest in microbes, "actually we are very much interested in microbes but the microbes (.) quite difficult (.) because once you supply to them they can cultivate themselves" (lines 494-496). This was a display of solidarity that 
attempted to repair the relationship with A1. B1 cooperated to reduce A1's loss of face. A1 in return reciprocated with solidarity politeness when he took up B1's subtopic, and portrayed UPM and JC as cooperators. A1 responded, "in fact the product ah we interested also in microbes but for bio plastic only (.) if we can make that (.) we can be billionaires already (.) the whole world can be free of plastic (.) but it is not perfect yet (.) so we want help also (.) you just imagine ha if UPM and your company or the Japanese company can produce bio plastic after using put in the soil (.) disappear biodegradable (.) biodegradable ah (.) we can solve the world's environmental problems" (lines 497-506). Rapport and goodwill were reestablished between the parties. The efforts at relational work from lines $494-507$ can be interpreted as "cooling out", a phenomenon that occurs after a participant has to give in to the other. This phenomenon was first described by Goffman (1952). Goffman notes that in 'cooling out' the participants in a group try to help the participant who gave in to cope with his failure. They present themselves as cooperative, which help to regain the cooperation of the person who had to give in. The segment from lines $494-507$ gives evidence of a cooling out sequence, where B1 tried to help A1 cope with his (A1) giving in to his (B1) want, by making small talk to rebuild rapport.

This network shows how power can be exercised, resisted, negotiated and regained without being disruptive. In this network, the interplay of power and politeness underlined both parties interacting style. A1 exercised power when proposing. Power was exercised when he constrained the action environment of B1 with a directive and through interruptions. His display of power, however, was balanced with solidarity politeness in the giving of reasons that claimed reflexivity between the parties.

The interplay of power and politeness was also in B1's interacting pattern. He resisted A1's proposal with a display of power. Silence was the strategy used. It constrained A1 into 
reassessing his action environment. A1 consequently gave in and accommodated B1's wants. However, B1's power move was not destructive as it was masked as deference politeness. Although silence displayed power, it also gave deference to A1. Deference was exercised by being discreet about disagreement. By avoiding direct disagreement, the strategy can be said to have given deference to A1.

Nevertheless, as a result of B1's display of power, power had to be renegotiated between the parties. The network shows how this was done without resulting in disruption. Politeness played a major role in negotiating power. Solidarity politeness, exercised in a 'cooling out' sequence, worked to reestablish the power positions of the parties in the network. The parties worked together collaboratively to reclaim their positions in the network. Both parties emphasized solidarity with each other. They ratified each other's topic initiating move. 'Cooling out' was a strategy for displaying relational work following an exercise of power where one party had to give in to the other. It was an important sequence for reestablishing ties for further cooperation in the negotiation and interaction, and probably more so in the network above as it was the higher-ranking participant who gave in.

It is hoped the two networks above display the workings of the model proposed in this article.

\section{Concluding Remarks}

In summary, I reiterate that the model for analysing power and politeness offered in this paper is eclectic; it was generated from a triangulation of theoretical perspectives of universal status. This framework has been successfully applied for analysing business negotiations between Malay and Japanese businessmen in Paramasivam 2004, and it may have universal applications to speech 
genres other than negotiations as well as cultural contexts other than interactions between Malays and Japanese. It is anticipated the applicability of this model is tested using both interactions in similar situations as well as other situations. In closing, I hope the model helps other scholars of power and politeness develop an eye for the phenomenon enabling them to investigate it in discourse.

\section{References}

Abdullah, A. 1996. Going Global: Cultural Dimensions in Malaysian Management. Kuala Lumpur: Malaysian Institute of Management.

Davis, K. 1988. Power under the Microscope. Dordrecht: Foris Publications.

Doi, T. 1976. The Japanese Patterns of Communication and the Concept of Amae. In L. Samovar \& R. Porter (eds.), Intercultural Communication: A Reader 188-193. Belmont, CA: Wadsworth.

Flick, U. 1998. An Introduction to Qualitative Research. London: Sage Publications.

Goffman, E. 1952. On Cooling the Mark out: Some Aspects of Adaptations to Failure. Psychiatry 15, 451-463.

. 1974. Frame Analysis: An Essay on the Organization of Experience. Harmondsworth: Penguin Books.

. 1981. Forms of Talk. Philadelphia, PA: University of Pennsylvania Press.

Hall, E. 1966. The Hidden Dimension. New York: Doubleday.

Hofstede, G. 1991. Management in a Multicultural Society. Malaysian Management Review 26.1, 3-12.

Janney, R. \& H. Arndt. 1993. Universality and Relativity in Cross-cultural

Politeness Research: A Historical Perspective. Multilingua 12.1, 13-50.

Locher, M. 2004. Power and Politeness in Action. Berlin: Mouton de Gruyter.

Mao, L. 1994. Beyond Politeness Theory: "Face" Revisited and Renewed. 
Journal of Pragmatics 21, 451-486.

Marriott, H. 1995. The Management of Discourse in International Sellerbuyer Negotiations. In K. Ehlich \& J. Wagner (Eds.), The Discourse of Business Negotiation 103-126. Berlin: Mouton de Gruyter.

Matsumoto, Y. 1989. Politeness and Conversational Universals: Observations from Japanese. Multilingua 8, 207-221.

Mulholland, J. 1991. The Language of Negotiation. London: Routledge.

Nakano, Y. 1995. Frame Analysis of a Japanese-American Contract Negotiation. Ph.D. Dissertation. Columbus, OH: A Bell \& Howell.

Omar, A. 1995. Indirectness as a Rule of Speaking among the Malays. In Z.

Majid \& L. Baskaran (eds.), Rules of Speaking: Verbal Interactions of Play 47-60. Petaling Jaya: Pelanduk Publications.

Paramasivam, S. 2004. The Play of Power and Politeness in Negotiation Discourse: A Case Study. Ph.D. Dissertation. Bangi: Universiti Kebangsaan Malaysia.

2006. Coming to Grips with the Analysis of Language and Power. Korean Journal of Applied Linguistics 22. 2, 1-25.

Rees, E., R. Cervero, L. Moshi, \& A. Wilson. 1997. Language, Power, and the Construction of Adult Education Programs. Adult Education Quarterly 47. 2, 63-77.

Rehbein, J. 1995. International Sales Talk. In K. Ehlich \& J. Wagner (eds.), The Discourse of Business Negotiation 67-102. Berlin: Mouton de Gruyter.

Savage, G., J. Blair, \& R. Sorenson. 1999. Consider Both Relationships and Substance when Negotiating Strategically. In R. Lewicki, D. Saunders, \& J. Minton (eds.), Negotiation: Readings, Exercises and Cases 32-49. Boston, MA: Irwin McGraw-Hill.

Watanabe, S. 1993. Cultural Differences in Framing: American and Japanese Group Discussions. In D. Tannen (ed.), Framing in Discourse 176-209. New York: Oxford University Press.

Watts, R. 1991. Power in Family Discourse. Berlin: Mouton de Gruyter. 